\title{
Ecological Development and Global Climate Change: A Cross-National Study of Kyoto Protocol Ratification
}

\author{
SAMMY ZAHRAN \\ Department of Sociology, Colorado State University, Fort Collins, \\ Colorado, USA
}

EUNYI KIM

Department of Communication, Incheon University, Incheon, Korea

\section{CHEN}

Department of Sociology and Institute for Science, Technology, and Public Policy, Texas A\&M University, College Station, Texas, USA

\section{MARK LUBELL}

Department of Environmental Science and Policy, University of California, Davis, California, USA

\begin{abstract}
This article adapts a theory of ecological modernization to characterize countries by their economic, political, and cultural development to estimate their structural and strategic readiness to commit and comply with the Kyoto Protocol. Hypotheses logically derived from ecological modernization theory perform as expected, with substantial variation in Kyoto Protocol ratification explained by our variable pool. Results from logistic and Cox proportional hazards regression tests show that democratic openness, gross domestic product (GDP) output per unit of energy input, $\mathrm{CO}_{2}$ emissions per capita, and record of international cooperation on transboundary environmental problems significantly predict whether or not a country is party to the Protocol, and how quickly a country submits an instrument of ratification.
\end{abstract}

Received 18 April 2005; accepted 29 January 2006.

This material is based on research conducted by the Institute for Science, Technology, and Public Policy at Texas A\&M University and supported under award NA03OAR4310164 by the National Oceanic and Atmospheric Administration (NOAA), U.S. Department of Commerce. The statements, findings, conclusions, and recommendatiendations are those of the authors and do not necessarily reflect the views of the National Oceanic and Atmospheric Administration or the Department of Commerce.

Address correspondence to Sammy Zahran, Department of Sociology, Colorado State University, B-258 Clark Building, Fort Collins, CO 80523-1784, USA. E-mail: sammy. zahran@colostate.edu 
Keywords climate change policy, development, ecological modernization, global climate change, Kyoto Protocol

Climate scientists have observed increased atmospheric concentrations of greenhouse gases (GHGs). Among GHGs, carbon dioxide emissions are thought to be a major cause of climate change. Scientists agree that significant variation in climate change is explainable by human action, particularly the burning of fossil fuels (IPCC 2001). In the words of Naomi Oreskes (2004), "There is a scientific consensus on the reality of anthropogenic climate change." Global temperature may increase by $5.8^{\circ} \mathrm{C}$ compared with 1990 levels (IPCC 2001). Risks accompany increased global temperature, including rising sea levels, increased precipitation, glacial melting, extreme weather, coastal flooding, drought, loss of plant and animal species, and increased malaria transmission (De Leo et al. 2001; Parry et al. 2001).

Global climate change is a "tragedy of the commons" (Hardin 1968). Climate is a common resource that cannot be readily fenced or allocated according to need. Garrett Hardin (1968) used the concept of "tragedy" to denote the expected degradation of environmental resources when owned commonly. A tragedy unfolds when common-pool resources are exhausted by withdrawals (e.g., overgrazing of land) or additions (i.e., the emission of toxic fumes into the air). The degradation of commonpool resources is an ancient problem of individual versus group interests. Aristotle observed: "For that which is common to the greatest number has the least care bestowed upon it. Everyone thinks chiefly of his own, hardly at all of the common interest." In others words, that which is rational for an individual may produce irrational consequences for the group.

Global climate is at risk because rules of behavior ineffectively coordinate individual and group interests. All things held equal, it is rational for an individual to withdraw from and add to common-pool resources until failure (Dietz et al. 2003). The failure of common-pool resources harms all. In Hardin's (1968, 162) words: "Ruin is the destination toward which all men rush, each pursuing his own best interest in a society that believes in the freedom of the commons." Coordination of individual and group interests is not an escape-proof trap (Ostrom 1990).

The Kyoto Protocol (hereafter, the Protocol) is an international treaty to govern the "commons" problem of global climate change. The Protocol commits signatories to targets and timetables for the reduction of GHG emissions. By 2012, industrialized (or Annex I) countries must reduce GHG emissions by 5\%. Developing countries like China and India (non-Annex I) are exempt because of their comparatively smaller contribution to the volume of GHGs present in the atmosphere ${ }^{1}$ (Lutzenhiser 2001). All parties to the Protocol must design and implement climate change mitigation and adaptation policies, and promote the development of climate sensitive technologies. The Protocol distributes the costs of reform unevenly by country status, but all signatories face transition costs. For the Protocol to enter force, at least 55 parties to the convention must ratify the Protocol, including Annex I parties that account for $55 \%$ of 1990 carbon dioxide $\left(\mathrm{CO}_{2}\right)$ emissions. On February 16, 2005, the Protocol entered force with Russia's ratification instrument.

The Protocol is an imperfect instrument. From the left, it has been criticized for having too many loopholes and inadequate compliance provisions (van Kooten 
2003), for undervaluing intergenerational equity (Gardiner 2004), and for not going far enough to effectively reverse the trend of global warming. From the right, the Protocol has been criticized as harmful to commercial interests and economic growth, for being based on uncertain scientific data, and for failing to achieve fairness by not specifying binding targets or timetables for nonindustrialized countries (Rollings-Magnusson and Magnusson 2000). For these reasons, and others, the Bush Administration officially withdrew the United States from participation in Kyoto in 2001.

Apart from Protocol design problems, what accounts for U.S. nonparticipation? What about Australia's nonparticipation? Why do some countries ratify, while other countries stall, foot-drag, and resist ratification? And, what accounts for the speed at which a country commits itself to costly climate change reforms? Scholars of comparative foreign policy with case studies and small-sample quantitative methods have identified strategic reasons that govern cooperation and conflict between nation-states on environmental treaties. However, our understanding of why countries ratify or reject environmental treaties "is found wanting" (Roberts et al. 2004, 23). Our knowledge is wanting because few scholars explicitly link strategy and structure in the context of coherent theory. The questions just asked are answerable if we couple understanding of the strategic motives of international environmental politics (see Young 1994; Dietz et al. 2003) with understanding of the structural features of a country that circumscribe or enable its ability to mitigate global climate change by reducing GHG emissions.

In this article, we investigate strategic and structural factors that explain variation in Kyoto Protocol ratification and the pace at which countries move to ratify. We adapt a theory of ecological modernization to characterize countries by their economic, political, and cultural development in terms of their structural and strategic readiness to commit to and comply with the Kyoto Protocol. Ecological modernization theory is a reasonable framework for organizing literature in environmental social science on the behavior of nation states. The theory is synthetic, incorporating structural insights from development and international political economy literatures as well as strategic insights from rational choice institutionalism and economics. Our study is organized into four sections. First, we provide a discussion of ecological modernization theory. Second, we explain our research design, outlining data sources and variables operations and specifying testable predictions. Third, we present results from logistic regression and Cox proportional hazards regression tests. Last, we revisit theoretical claims in relation to findings.

\section{Ecological Modernization Theory}

The German sociologist Joseph Huber is credited with developing ecological modernization theory (EMT). EMT is used to analyze how societies organize economic, political, and cultural institutions to address environmental crises. Mol (2003, 3) defines the process of ecological modernization as the "centripetal movement of ecological interests, ideas and considerations in the social practices and institutional developments of modern societies." Ecologically modernized societies incorporate principles of environmentalism in the design of institutions to regulate human interactions with nature. A market economy, democratically elected government, and constitutionally guaranteed rights and freedoms are necessary institutions for ecological modernization. These institutions function as reflexive mechanisms with the potential to soften the human footprint on the planet. 
EMT is somewhat controversial because it advocates accelerated development - regarded by other scholars as responsible for the degradation of the environment in the first place (see Foster 1994; O'Connor 1998; Schnaiberg 1980). Critics of EMT, from ecological Marxists to adherents of the "treadmill of production" school of thought, regard the idea of accelerated development as wrongheaded. York, Rosa, and Dietz (2003) argue that modernization does not improve environmental conditions; instead, it "drives environmental deterioration" (York et al. 2003, 44). EMT rejects the belief that environmental degradation necessarily increases monotonically with development, arguing instead that countries reach "turning points" in their developmental trajectories at which rates of environmental degradation subside. The logic of EMT is similar to the environmental Kuznets curve (EKC) in economics, but places greater emphasis on noneconomic factors for the gradual decline in rates of pollution. Decline occurs because as countries develop they achieve increased energy efficiency, apply stringent and costly pollution controls, educate their publics in science and environmental values, and manifest politically influential environmental movements that emerge in response to environmental deterioration ${ }^{2}$ (Roberts and Grimes 1997; Fisher and Freudenburg 2001). These changes in economy, politics, and culture enable a country to assimilate "environmental signals from world society" on effective environmental reforms (Frank et al. 2000, 105).

Ecological modernization (EM) denotes a process of structural change in economic, political, and cultural institutions that directly affect environmental outcomes. Structural change generally proceeds incrementally, but "it is not necessarily a process of change that is evolutionary, deterministic, irreversible or smooth" (Murphy 2001, 3, our emphasis). Research shows that countries vary considerably in the degree to which ecologically modernized institutions are present (Spaargaren and Mol 1992; Sonnenfeld and Mol 2002a). Some scholars suggest that EMT is applicable only for developed countries (Fisher and Freudenburg 2001). Such scholars maintain that countries must transition through stages of economic development - a process Huber $(1982,20)$ metaphorically defines as the "ugly caterpillar that transforms itself into a beautiful butterfly." We find this developmental logic unsatisfactory. ${ }^{3}$ Countries can leapfrog technologically and institutionally. Examples of leapfrogging abound in literatures on technological diffusion (see Chen et al. 2004; Brezis, Krugman, and Tsiddon 1993), the spread of models of commerce and governance (see Fukuyama 1992), and the global export of environmental reforms (see Mol 2003).

An example of a leapfrogging country is Costa Rica. Data show that Costa Rica has high efficiency in terms of gross domestic product (GDP) output per unit of energy input. Costa Rica has acquired an international reputation for conservation policy, with $25 \%$ of its territory designated as protected area (Evans, 1999). However, Costa Rica compares relatively badly to Organization for Economic Cooperation and Development (OECD) countries on measures of economic output. Costa Rica's ecological "turning point" occurred comparatively early in its developmental arc. Conversely, economically developed countries like the United States and Australia score relatively poorly on measures of ecological sustainability. The pace of ecological modernization is slower for these countries. This suggests that there is no universal turning point, nor is there a necessary path that all countries must follow to modernize ecologically. In Sonnenfeld and Mol's words $(2002 \mathrm{~b}, 1460)$, change "is not a unilinear process unfolding automatically 
and inevitably toward enhanced environmental capacities and performances." Therefore, we do not believe EMT is applicable only to developed countries. It is a reasonable framework to empirically assess all countries on a range of attributes associated with ecological development.

Three dimensions of ecological development are emphasized in the literatureeconomy, politics, and culture (Mol 1995). The economic dimension of ecological modernization emphasizes the restructuring of production to increase energy efficiency and decrease environmental externalities. This involves a series of technical solutions to product cycles from resource extraction to fabrication to solid waste disposal, at each phase of the product cycle increasing efficiency in energy, water, chemical, and bulk material inputs to significantly reduce pollution outputs. These "refinements of production" (Huber 1982) transform the composition of an economy from heavy to lighter industry (Murphy and Gouldson 1998).

In the conversion from heavy to light economy, the "enduring conflict" (see Schnaiberg 1980; Schnaiberg and Gould 1994) between economy and environment is partially solved. In lighter economies, environmental reforms can function as incentives for technological innovation and the formation of new markets. ${ }^{4}$ Innovation can increase productive efficiency. With less energy required to produce the same quantity of commodities, industries gain considerable economic value. Efficiency gains help preserve resources and reduce pollution. Therefore, fixing an environmental problem "can make industry more efficient and may actually generate future growth" (Murphy and Gouldson 1998, 8).

A lighter economy requires effective governance. The political dimension of ecological modernization stresses democratic openness as an institutional requirement for balancing economic and environmental imperatives. Mol and Buttel (2002) argue that flexible governance, extensive civil liberties and political rights, and participatory policymaking characterize ecologically modernized countries. The presence of such democratic institutions increases the probability that environmental and economic values are given fair consideration in policy formation (Leroy and van Tatenhove 2000). Democracies create "greater social and political activity as well as heightened political awareness and participation," and vice versa (Vassilev 1999, 566). According to Murphy (2001), government policies spur ecological modernization by creating favorable conditions for environmentally sound production and consumption.

To modernize production, governments use a mix of instruments from public investment in research and development $(\mathrm{R} \& \mathrm{D})$, to organizing private-sector consortia, building networks between stakeholders to reduce policy friction, and linking environmental imperatives to insurance, credit, pension, and investment capital services (Murphy 2001). Ecologically modernized countries couple market-based approaches with traditional command-and-control regulation to coordinate production-side environmental problems (Spaargaren 2000; Mol 1995). To modernize consumption, governments promote environmentally friendly lifestyles with education campaigns and tax mechanisms. Tax mechanisms internalize environmental costs, with rewards for purchase of green commodities and penalties for consumption activities harmful to the environment.

Because many environmental problems are transboundary, ecologically modernized countries see international cooperation as a strategic component of effective environmental governance. According Sonnenfeld and Mol (2002b, 1457) nationstates are no longer "the sole responsible agency for designing, implementing, and 
solving environmental problems within the borders of a country." Ecological modernized countries do not see the world as an anarchic game between egoists "inherently doomed to persistent zero-sum conflict" (Keohane 1988, 381). Normatively speaking, EM theorists see the world as comprised of interdependent states with common interests that require treaties and institutions "as functional solutions to efficiency problems" (Roberts et al. 2004, 26). Ecologically modernized countries have a higher propensity to engage in international environmental treaties and institutions. Countries belonging to many treaties and institutions demonstrate a willingness to use cooperative strategies in instances where collective-action dilemmas obtain, seeing the strategic value of multilateral relationships. The willingness to cooperate internationally is a partial function of strong internal democracy and the presence of an environmentally concerned public. This brings us to the third dimension of ecological modernization-culture.

The cultural dimension of ecological modernization emphasizes the values and behaviors of mass publics toward nature. Publics that value aesthetics, identity, and self-actualization over economic growth characterize ecologically modernized countries. Inglehart (1990) calls this value orientation postmaterialism. Publics with postmaterialist values exhibit more concern for quality of life, education, and environmental preservation. Postmaterial publics are more likely to belong to environmental groups, donate money to environmental protection efforts, and engage in environmentally friendly behaviors (Kidd and Lee 1997). Schultz and Zelezny (1998) find a positive correlation between postmaterial values and proenvironmental attitudes and behaviors. Following a hierarchy of needs logic (see Maslow 1954), Inglehart (1990) argues that postmaterial values generalize in a society after economic security is achieved. Assuming Inglehart is correct, higher levels of environmental concern ought to exist in economically developed countries than in less developed countries. The evidence for this is mixed.

Ulrich Beck (1994) shows how environmentalism is a principal axis of postWorld War II politics in developed countries. Brechin and Kempton (1994) from cross-national survey data show that respondents in less developed countries like India and Mexico reflect greater concern for environmental protection than respondents in advanced economies like Finland and Japan. Frank et al. $(2000,99)$ argue that the affluence thesis articulates poorly with the historical record of environmental reform, arguing that "most countries have embraced environmental protection, not just the rich." Whatever the level of economic development, studies show that environmentalists are drawn disproportionately from the ranks of "social and cultural specialists" like teachers, social workers, artists, journalists, college professors, and public service employees (Cotgrove and Duff 1981; Kriesi 1989). Educated strata of society are the carriers of ecological consciousness. Therefore, to ecologically modernize cultural institutions, countries must invest in education to increase ranks of social and cultural specialists.

Overall, these three dimensions of EMT alert us to the importance of institutions in constituting a country's structural readiness for environmentally sustainable development, and shaping a country's strategic willingness or ability to solve transboundary environmental problems that implicate the globe. Measuring a country's level of ecological modernization can shed light on the probability it will commit to solving the commons problem of global climate change. In the next section, we detail our measurement decisions for assessing a country's level of ecological modernization for prediction of variation in Kyoto Protocol ratification. 


\section{Data Sources, Variable Measures, and Hypotheses}

Our measurement of ecological modernization, as theorized in the literature, is divided into three dimensions: (1) political, (2) economic, and (3) cultural. On the political dimension, we measure a country's internal and external political attributes. Our internal politics variable estimates a country's level of political rights, civil liberties, and democracy. These internal political features define a country's institutional reflexivity and receptivity to environmental reform. Our external politics measure approximates a country's propensity for strategic cooperation on transboundary environmental problems. On the economic dimension of ecological modernization, we measure two features of a country's economy that are highly sensitive to stabilization of carbon dioxide emissions as delineated by the Kyoto Protocol-energy efficiency (with higher scores increasing the odds of ratification) and carbon dioxide emissions per capita (with higher scores decreasing the odds of ratification). On the cultural dimension of ecological modernization, we measure a country's level of educational development as a proxy for levels of environmental and postmaterial values. It is important to note that these variables are not exclusive to EMT. Political variables can be used to estimate elements of neo-realism in international relations research, and economic variables can be used to operationalize observations in microeconomic and rational choice theories. Our contention is that the combination of these variables is unique to EMT.

Our internal politics measure is an additive scale $($ alpha $=.968)$ comprised of three standardized items: civil liberties, political rights, and democracy score. Civil liberties and political rights scores are derived from the Freedom in the World survey of 2003. On political rights, countries are evaluated on electoral openness, pluralism and participation, and government functionality. On civil liberties, countries are measured on freedoms of expressions, assembly, education, religion, and norms of law enforcement. A team of analysts and senior academic advisors with expertise in comparative politics scores countries from 1 to 7 . Countries scoring 1 on the political rights scale are characterized by free and open elections, a competitive political party system, and the relative absence of political corruption, violence, and legal discrimination against minority groups. Countries scoring a 7 on the political rights scale are marked by violence, fragmented authority, and generalized oppression. Countries scoring 1 on civil liberties are distinguished by rule of law and equality of opportunity. Persons in countries scoring 7 on the civil liberties scale have severely restricted rights of expression, association, and ownership of private property (Freedom House 2003). A strong correlation obtains between a country's political rights and civil liberties (Pearson's $r=.929)$. Political rights and civil liberties scores are reverse coded, standardized, and combined with a standardized democracy score derived from the Polity IV Project database (Marshall and Jaggers 2002).

Institutionalized Democracy in 2000 is an 11-point scale based on three features of regime legitimacy: openness and competitiveness of executive recruitment, the effectiveness of executive constraints, and the competitiveness of politics (Marshall and Jaggers 2002). A state receiving a score of 10 is a "mature and internally coherent democracy... operationally defined as one in which (a) political participation is fully competitive, (b) executive recruitment is elective, and (c) constraints on the chief executive are substantial" (Marshall and Jaggers 2002, 14). The strong correlation between environmental activism and the democratic status of a country (Brechin 
2003; Dunlap et al. 1993) suggests that countries with highly developed internal political institutions are more likely to commit to climate change mitigation because of greater institutional receptivity to environmental values.

Our external politics measure is an additive scale (alpha $=.649)$ comprised of four standardized items: Vienna Convention participation; membership in environmental intergovernmental organizations; Montreal Protocol Multilateral Fund participation; and Cartagena Protocol ratification status. Vienna Convention participation is measured as a five-attribute scale $(0=$ country is not a signatory to the Vienna Convention for the protection of the ozone layer; $1=$ country ratified Montreal Protocol only; $2=$ country ratified the above plus the London Amendment, $2.5=$ country ratified the above plus the Copenhagen Amendment, and $3=$ country ratified the above plus the Montreal Amendment). Membership in environmental intergovernmental organizations is a ratio variable, ranging from 2 memberships (Bhutan) to 35 memberships (France). The Montreal Protocol Multilateral Fund participation variable combines payments and receipts by countries from the fund. Payments and transfers were standardized and the higher of the two $z$-scores was assigned to each country. The last item, Cartagena Protocol ratification status, is a two-attribute variable $(0=$ not ratified, $1=$ ratified $)$. All items are derived from Columbia University's Center for International Earth Science Information Network database of 2002 (Environmental Sustainability Index 2002). The database contains 5 statistical components, 20 indicators, and 68 corresponding variables measuring environmental sustainability. The external politics measure captures the general willingness of a country to cooperate strategically with other countries to solve transboundary environmental problems. Therefore, we hypothesize that countries with demonstrated histories of international cooperation on global environmental problems, reflecting propensities for reciprocal and multilateral strategies to solve collective action dilemmas, are more likely to ratify the Kyoto Protocol.

Our first economic measure of ecological modernization is GDP per unit of energy. The GDP per unit of energy is a ratio variable of energy efficiency comparing estimates of real GDP across countries relative to units of commercial energy use. This variable is taken from the United Nations Human Development Report (UNHDP 2003). GDP data are adjusted by reference to Purchasing Power Parity tables derived from the International Comparisons Program (UNHDP 2003). Commercial energy consumption data are derived from national energy balance sheets and converted to an oil equivalence measure. Traditional fuels like animal and vegetable waste, fuel wood, and charcoal are excluded from the measure. GDP is divided by energy input to derive the ratio. Differences in this ratio over time and across countries reflect structural changes in an economy, changes in the energy efficiency of production, and differences in fuel mixes. In principle, the higher a county's GDP per unit of energy ratio, the greater is the energy efficiency. Countries with greater energy efficiency are more ecological modernized in terms of their productive forces. Therefore, we hypothesize that countries with higher energy efficiency are more likely to ratify the Kyoto Protocol because of lower selective costs imposed by policy enactment. That is, countries with relatively higher energy efficiency can transition more easily to the objectives set by the Protocol.

Our second economic measure of ecological modernization is carbon dioxide emissions per capita. The carbon dioxide emissions per capita variable is calculated by dividing carbon dioxide emissions measured in metric tons by the number of people residing in a nation (UNHDP 2003). This variable is taken from the United 
Nations Human Development Report (2003). National carbon dioxide emissions are estimated from detailed data on consumption of solid, liquid, and gaseous fuels, gas flaring, and the production of cement (UNHDP 2003, 350). Energy or environment ministries usually compile emission inventories. Where national emission inventories are absent, official sources are supplemented by nongovernmental sources and estimates. National reports follow the IPCC guidelines on sources of anthropogenic carbon dioxide emissions. Carbon dioxide emissions result from energy production and use, accounting for the largest share of greenhouse gases associated with global warming. We hypothesize that countries with comparatively high levels of carbon dioxide emissions are less likely to commit to reduction targets delineated in the Kyoto Protocol because of the high selective costs of restructuring energy production and consumption practices. Ecologically modernized countries in terms of productive efficiency and lower levels of carbon dioxide externalities are more capable structurally to commit to global climate change policies. Overall, the political economic costs of mitigation and adaptation are comparatively lower for ecologically modernized countries (Dolsak 2001).

The last independent variable in our prediction equation is the education index. This measure captures the cultural dimension of ecological modernization. The education index is a standardized ratio variable (UNHDP 2003). The education index measures a country's relative development in adult literacy and combined primary, secondary, and tertiary gross enrolment. The adult literacy component of the index is weighted more heavily than combined gross enrolment. Because internationally comparable and comprehensive data on environmental values are available for selected countries only, we use the UNHDP education index (2003) as a proxy. Strong correlations obtain between the education index and environmental concern measures on the Health of the Planet Survey (i.e., percent of respondents indicating that global warming is a very serious problem, $r=.519)$, as well as between the education index and postmaterialist measures on the World Values Survey of 2000 (i.e., importance of leisure over money, $r=.574$ ) (http://www.worldvaluessurvey.org 2000, accessed January 10, 2005). Therefore, we hypothesize that countries with higher education index scores, reflecting greater concern for the global environment and postmaterial values, are more likely to ratify the Kyoto Protocol than countries with relatively lower education index scores.

For analytic parsimony, we also combine our internal and external measures of politics for a more general measure of the political dimension (alpha $=.674)$ of ecological modernization. The statistical association and theoretical linkage between a country's internal democratic structure and historical willingness to cooperate strategically with other countries to solve common environmental problems (see Frank et al. 2000) validate the measure. We also combine our two measures of the economic dimension $($ alpha $=.615)$. We flipped the direction of carbon dioxide per capita measure for proper addition. Because of insufficient cross-national survey data on attitudes toward global warming and climate change, we also use the education index in reduced models. These measures of ecological modernization are tested in separate regression models.

Our dependent variable, Kyoto Protocol ratification, is measured dichotomously. Countries ratifying the Kyoto Protocol as of July 8, 2004, are assigned a score of 1 . Nonratification countries receive a score of 0 . We also conduct a duration model of ratification, estimating the pace of ratification in days. As of July 8, 2004, 84 countries signed and 125 countries ratified, accepted, acceded, or approved the 
Kyoto Protocol. Data on ratification status were obtained from the United Nations Framework Convention on Climate Change web site (UNFCCC 2004).

\section{Results}

The data set includes 108 countries. All 39 Annex I countries are present in the dataset, minus Liechtenstein, Luxembourg, and Monaco, for which comprehensive data are unavailable. The remaining 72 cases are drawn from the pool of non-Annex I countries, $59.46 \%$ of which had ratified the Protocol by July 8,2004 . In our sample, 74 countries had ratified and 34 had not ratified the Protocol by June 8, 2004. The adoption rate of the Kyoto Protocol for sampled countries is S-curved. The S-curve for Kyoto Protocol ratification is a diffusion of innovation signature (Tarde 1903). The S-curve is explainable by the group of European countries that ratified the Protocol at 45 to 50 months from the moment it was opened for signature on March 16, 1998. Within days of European ratification, several other nations (including Japan) committed to the Protocol. Observers defined the maneuver by European countries to ratify the Protocol as a strategic response to U.S. refusal to observe the treaty (Hovi et al. 2003).

First, we graphically array countries on dimensions of ecological modernization marked by ratification status. Figure 1 is a scatter plot of political and economic dimensions. The correlation between political and economic dimensions is weak and statistically insignificant $(p=.913)$. This suggests that engineering structural change toward ecological modernization is profoundly difficult, involving solutions to independent dimensions of social structure. By dividing the plot into quadrants of High-High, Low-Low, High-Low, and Low-High, a structural-strategic logic of ratification is revealed. Countries characterized by high modernization on both dimensions have a higher probability of ratification, evident by the concentration of ratifying countries in the High-High quadrant of the plot. Conversely, nonratifying

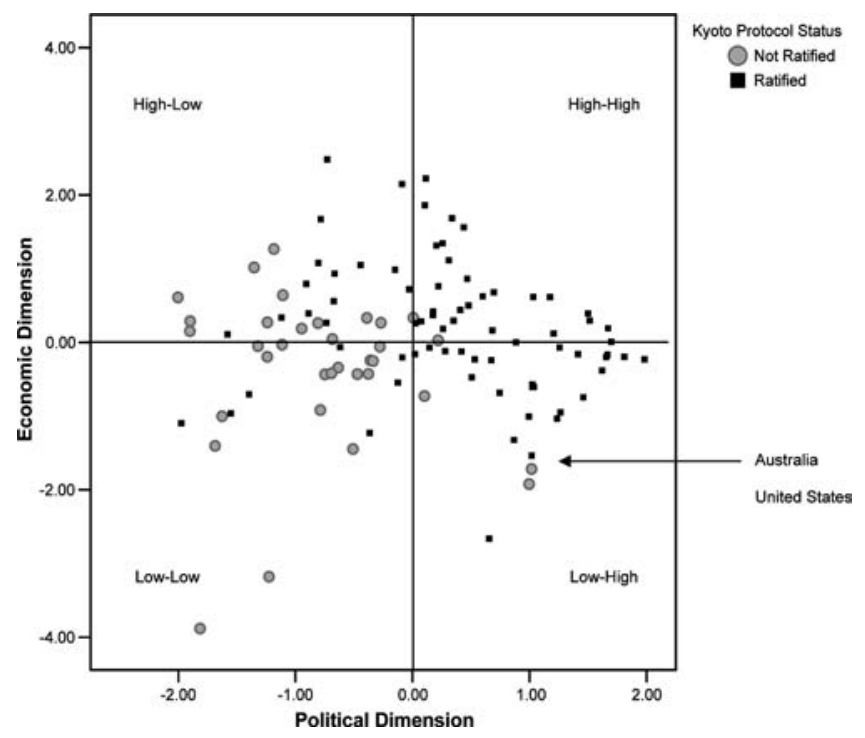

Figure 1. Two-dimensional scatter plot of Kyoto Protocol ratification status. 
countries are concentrated in the Low-Low quadrant. The United States and Australia are distinguished from ratifying countries by their comparatively lower developed economic dimension of ecological modernization. Both countries appear in the LowHigh quadrant of the graph.

Binary logistic regression models estimating the odds of ratification are presented in Table 1.

Model 1 performs well, explaining 56\% of variation in Kyoto Protocol ratification. All variables are significant. Both measures of political development are positively associated with ratification-internal politics $(B=.147, \mathrm{SE}=.049, p<.01)$ and external politics $(B=.241, \mathrm{SE}=.143, p<.10)$. The odds of Protocol ratification improve significantly as countries cultivate democratic institutions internally and cooperate internationally on other environmental issues. With regard to external politics, ratifying nations belong to a greater number of intergovernmental environmental organizations. Institutional perspectives in international relations theory posit that disputes between countries with different interests are manageable by global rule sets and institutions. Intergovernmental organizations function to reduce the transaction costs of negotiating agreements between nations. They also function to build norms of trust and reciprocity, increasing probabilities of future cooperation by an institutional spillover effect (Keohane 1988). Results suggest that countries ratifying Kyoto have histories of international cooperation on environmental issues.

Both economic measures of ecological modernization are significantly related to ratification. As a country's level of $\mathrm{CO}_{2}$ emissions per capita increases, the probability of ratification decreases $(\mathrm{B}=-.191, p<.05)$. For every unit increase in GDP output per unit of energy input, the odds of ratification increase by a multiplicative factor of $1.33(B=.287, p<.05)$. Our cultural modernization proxy of education index positively predicts Protocol ratification $(B=1.149, p<.05)$. Model 2 performs similarly well, with $55 \%$ of variation in Protocol ratification explained by the condensed variable pool. All dimensions of ecological modernization are statistically significant and positively correlated with ratification at the .01 alpha level. Ratifying countries have more educated publics, score higher on measures of internal and external politics, emit less $\mathrm{CO}_{2}$ per capita, and have higher energy efficiency.

Next, we conducted a Cox proportional hazards regression to test the effect of ecological modernization variables on the timing (in days) of Kyoto Protocol ratification. The average time to ratification is shorter for non-Annex 1 countries (1280 days, SD=559) than for Annex 1 countries (1548 days, SD = 179). This is possibly explainable by the lower political economic costs of ratification imposed on non-Annex 1 countries. Table 2 presents Cox regression results and omnibus tests of model coefficients. Column 1 shows that all variables but the education index are statistically significant. The hazard of ratification increases by a factor 1.088 for each unit increase in energy efficiency (GDP per unit of energy), representing an almost $9 \%$ increase in the hazard rate (or rate of ratification). The hazard rate decreases considerably (by $40 \%$ ) for every unit increase in $\mathrm{CO}_{2}$ emissions per capita (in metric tons). Political variables perform equally well, with the hazard rate increasing significantly with every unit increase in internal $(\exp (B)=1.067 ; p<.01)$ and external politics $(\exp (B)=1.092 ; p<.10)$ measures. Column 2 presents results for combined variables. Again, the political $(\exp (B)=1.781 ; p<.01)$ and economic $(\exp (B)=1.421 ; p<.01)$ dimensions of 


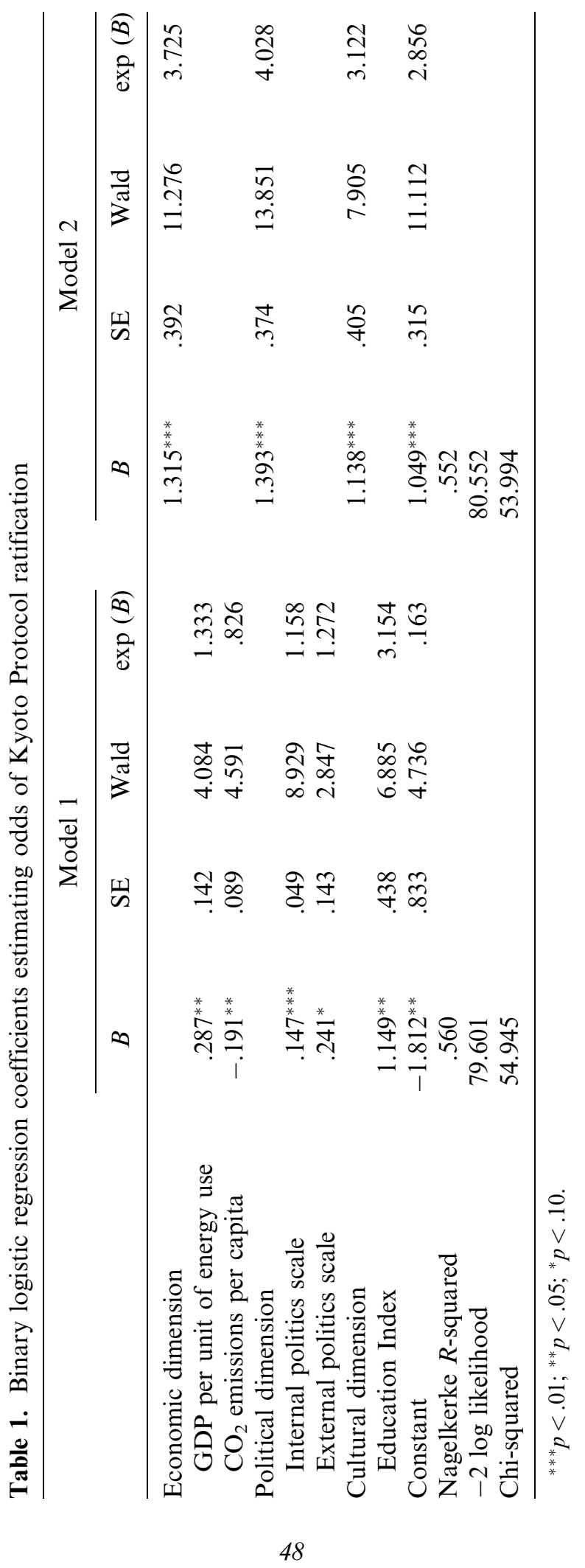




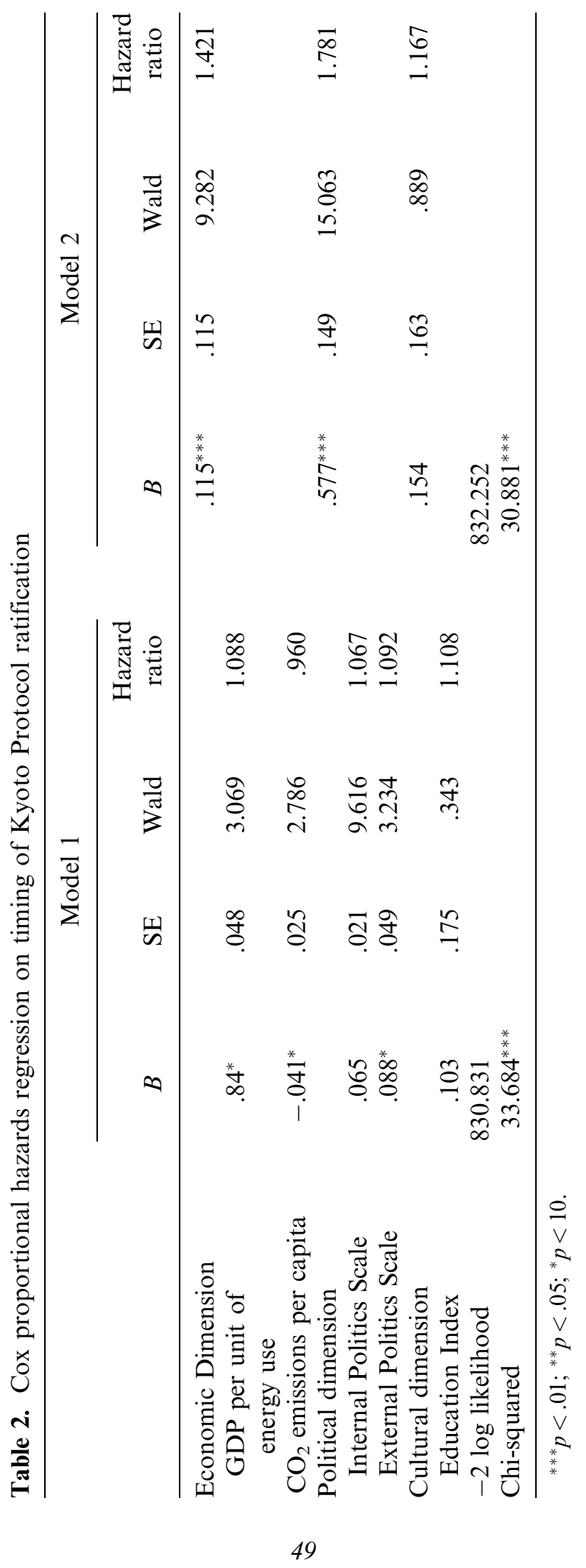


ecological modernization significantly predict the timing of ratification. Overall, results support our hypotheses and illustrate the analytic value of EMT in demarcating ratifying from nonratifying nations and in predicting the timing of ratification.

\section{Conclusion}

The main contribution of this analysis is to demonstrate the analytic value of ecological modernization theory in deriving testable hypotheses on variation in Kyoto Protocol ratification. We argue that a country's level of ecological modernization, as indicated by political, economic, and cultural indictors, reflects its structural and strategic readiness to ratify the Kyoto Protocol. Consistent with EMT, results indicate that societies characterized by extensive civil liberties and political rights, high energy efficiency, low carbon dioxide emissions per capita, high education levels (reflecting the presence of an environmentally aware and concerned public), and records of international cooperation on other transboundary environmental issues are significantly more likely to commit to the Protocol. The odds of Kyoto Protocol ratification increase significantly as countries modernize ecologically, cultivating the reflexive mechanisms of modernity. Furthermore, all variables less the education index predict the speed at which countries commit to Kyoto. It appears that an environmentally conscious public is important in steering a country toward commitment, but not important in predicting the speed of that commitment. The pace of ratification is determined by the reflexivity of political institutions and economic efficiencies.

Our results are compatible with models of cross-national variation in GHG emissions reported by York et al. (2003). With 1991 data, they find that urbanization and industrialization are positively associated with GHG emissions. For 2000 data, GDP per capita and $\mathrm{CO}_{2}$ emissions per capita remain highly correlated. In fact, substitution of GDP per capita for $\mathrm{CO}_{2}$ emissions per capita in our models produces the same results - GDP per capita is negatively related to Kyoto ratification. However, York, Rosa, and Dietz (2003) conclude that such results show the analytic weakness of EMT, and the analytic power of critical approaches like "metabolic rift" and "treadmill of production." This conclusion is too quick. Their assessment of EMT is based on a narrow operationalization of ecological modernization. Perfect fidelity between theory and measurement is difficult, but EMT is not reducible to GDP or the percentage of urbanized population. For EM theorists, modernization is not synonymous with economic growth or the size of an economy. As a prescription for reform, ecological modernization is about redesigning the institutions of modernity to achieve sustainable development. These institutions change, evident in the global spread of environmental rule sets that promote more sustainable human interaction with the biophysical environment (see Frank et al. 2000). Our study attempts to measure an ensemble of institutional dimensions that estimate how far a nation has come in the ecological modernization process.

Empirical support for EMT does not mean critical social science approaches are any less important. Critical approaches show how political economic design explains substantial variation in anthropogenic causes of environmental deterioration. However, critical theories perform questionably when asked to explain environmental improvements. Why, for example, has air quality in the United States improved markedly in the last 30 years (as estimated by criteria air pollutants)? EMT has an adequate explanation for this: Improvement in air quality is a function of institutional 
redesign by the promulgation of more stringent air quality standards. Did these changes occur because of some anonymous, invisibly governed, systemic correction as posited by economic orthodoxy? EMT and critical theories would answer no. Both would note sociological and political economic reasons for the improvement. If environmental development curves exist, and there is evidence to suggest that they do (see Frank, Hironaka, and Schofer 2000), critical theories and EMT are compatible approaches, picking up different tangents of the same curve - critical theories note where institutions of modernity have gone wrong (which is the bulk of the human story), and EMT notes where political economic design has gone right. Moreover, the variables used in our models are adequate indicators of elements other environmental social science theories. It is the combination of these variables that is specific to EMT.

Logistic and Cox regression models reveal the critical importance of political and economic dimensions of ecological modernization in partially resolving the collective action dilemma of global climate change. Interestingly, our analysis shows that political and economic dimensions of ecological modernization operate independently of each other. In other words, democratic openness and participation in intergovernmental environmental organizations do not correspond statistically with high economic output per unit or energy input or low carbon dioxide emissions per capita. The statistical independence of politics and economics in ecological transformation hints at the complexity of coordinating national interests with global interests to meet carbon dioxide reduction targets in the Kyoto Protocol. The commons problem of global climate change is exacerbated by the structural independence of these dimensions, reducing the ability of some countries to align their interests with the interests of the global totality. Countries that positively align political and economic dimensions of ecological modernization have a remarkably high propensity to commit to the Protocol-with 26 of the 28 countries falling in the High-High quadrant of our two-dimensional scatter plot ratifying the Protocol. Likewise, the probability of ratification decreases considerably as a country aligns these dimensions negatively, with only 7 of the 24 countries in the Low-Low quadrant ratifying the Protocol. ${ }^{5}$

Our analysis shows that countries differ significantly in their ability to align national interests with the interests of the global collectivity (as long as one assumes that ratification and implementation of the Kyoto Protocol is a collective interest). The new rules of conduct (i.e., targets and timetables) promulgated by the Kyoto Protocol not only set different responsibilities for different countries on the basis of their contribution to the problem (i.e., their historic impact on the common pool resource of global climate), but impose different transition or compliance costs on countries party to the Protocol as a function of varying social structure.

From a policy standpoint, these variables function as institutional domains to which specific policy mechanisms are attachable. For example, our results show that increasing energy efficiency significantly increases the likelihood that countries will formally commit to the global effort to reduce the anthropogenic causes of climate change. Governments can press the pedal of technological evolution by deploying a range of policy instruments including utility incentives, tax credits, energy-sensitive building codes, equipment efficiency standards, enabling alternative energy source markets, and so on. These specific mechanisms not only improve the structural readiness of a country to join the Kyoto Protocol, but can also move a country forward in the process of ecological development, increasing its structural capability to engage future 
transboundary environmental challenges, and can even increase its competitive fitness in the global economy (see Porter and van der Linde 1995; Lovins et al. 1999).

We started this article by characterizing global climate change as a tragedy of the commons in utero. It is a tragedy because, absent coercive leverage to coordinate individual and group interests in use/abuse of the common pool resource of climate, it is rational for an individual country to defect and ride the efforts of others. It is rational to ride others because the transition costs of participation are high, and the benefits of improved climate are nonexcludable. What our study shows is that countries vary considerably in their development of ecologically modernized institutions, and therefore vary by the transition costs imposed by ratifying the Kyoto Protocol (insofar as our structural assessments of countries roughly estimate the institutional reforms required to meet necessary conditions for ratification). The fact of varied transition costs makes it less rational for some countries to sign the Kyoto Protocol than others. The challenge for advocates of Kyoto is to construct parallel mechanisms and instruments that press down on the levers that improve structural readiness and lower the costs of transition. Ecological modernization theory can clue us in general directions.

\section{Notes}

1. China is second to the United States in total tonnage of $\mathrm{CO}_{2}$ emitted annually. India is fifth among all countries in total emissions. In per capita terms, China is 18th and India is 20th. In historical terms, China and India have emitted comparatively less $\mathrm{CO}_{2}$ than fully industrialized countries (Marland, Boden, and Andres 2000).

2. Ecological Marxists and treadmill-of-production theorists note that these positive changes spring from a second contradiction in market economies. To solve the first contradiction of capitalism - the systemic tension between forces and social relations of production-Western governments subsidized private enterprise while increasing the provision of primary social goods to ordinary citizens. These fiscal solutions set in motion an environmentally pernicious treadmill of production. Because of entropic irreversibility, environmental degradation increases the cost of production inputs with each turn in the circuit of accumulation. Also, as the environment is polluted by production externalities ordinary citizens are radicalized. Governments respond to citizen concerns by passing environmental laws and regulations. Such laws increase the costs of production, producing liquidity crises on the cost side of private enterprise (O'Connor 1998; Schnaiberg 1980). Ecological Marxists see the unfolding of the second contradiction of capitalism as a signal of the corruption of capitalist democracy, whereas EM theorists see opportunities for progressive reform. Just as environmental crises have a way of revealing architectures of social power (see Molotch and Lester 1975), they also reveal mechanisms of change and adaptation that can be adjusted to decrease probabilities of future crisis. EMT is an account of how societies discover mechanisms of change and reinforce them with incentives to achieve environmentally sustainable development.

3. The relationship between economic development and ecological modernization is not perfectly clear. Take for example the relationship between economic development and energy efficiency. Allowing for a slightly higher alpha level, we find a weak positive correlation between energy efficiency (GDP output per unit of energy input) and GDP per capita $(r=.185 ; p=.056)$, and a negative relationship between GDP per capita and a country's hydroelectric and renewable energy use as a percentage of total energy consumption $(r=-.183 ; p=.059)$. These results suggest that a purely economic concept of modernization may not fully explain why countries graduate to environmentally less harmful modes of production and consumption.

4. For example, in the United States the passage of numerous environmental laws in the 1970s and 1980s enabled extraordinary growth in the environmental industry in the 1990s. Data show that revenue (in constant dollars) for the environmental industry increased from $\$ 59$ 
billion in 1980 to $\$ 198$ billion in 1999 . For environmental industry segments like hazardous waste management, consulting and engineering, process and prevention technology, and air pollution control equipment, revenue increased by 418 to 1050 percent over the same time period (Statistical Abstract of the United States 1999-2001).

5. We ran logistic and Cox regression models predicting Protocol ratification with our education index and a recoded variable that assigns a score of 3 to countries falling in the High-High quadrant, a 2 to countries falling in either combination of High-Low, and a score of 1 to countries plotted in the Low-Low quadrant. In our logistic model, a unit increase in our recoded variable increases the odds ratio by $477 \%(\exp (B)=5.773, p=.000)$. In our Cox regression, a unit increase in our recoded variable increases the hazard rate by $76 \%(p=.000)$.

\section{References}

Beck, U. 1994. Risk society: Towards a new modernity. Newbury Park, CA: Sage.

Brechin, S. R. 2003. Comparative public opinion and knowledge on global climatic change and the Kyoto protocol: The U.S. versus the world? Int. J. Sociol. Social Policy 23(10):106-134.

Brechin, S. R. and W. Kempton. 1994. Global environmentalism: A challenge to the postmaterialism thesis? Social Sci. Q. 74(2):245-269.

Brezis, E. S., P. R. Krugman, and D. Tsiddon. 1993. Leapfrogging in international competition: A theory of cycles in national technological leadership. Am. Econ. Rev. 83(5): $1211-1219$.

Chen, Y., U. Farinelli, and T. B. Johansson. 2004. Technological leapfrogging-A strategic pathway to modernisation of the Chinese iron and steel industry? Energy Sustain. Dev. $8(2): 18-26$

Cotgrove, S. and A. Duff. 1981. Environmentalism, values, and social change. Br. J. Sociol. 32(1):92-110.

De Leo, G. A., L. Rizzi, A. Caizzi, and M. Gatto. 2001. Carbon emissions: The economic benefits of the Kyoto Protocol. Nature 413(6855):478-479.

Dietz, T., E. Ostrom, and P. C. Stern. 2003. The struggle to govern the commons. Science 302(5652):1907-1912.

Dolsak, N. 2001. Mitigating global climate change: Why are some countries more committed than others? Policy Stud. J. 29(3):414 436.

Dunlap, R. E., G. H. Gallup, Jr., and A. M. Gallup. 1993. Global environmental concern: Results from an international public opinion survey. Environment 35(9):7-15, 33-39.

Environmental Sustainability Index. 2002. Center for International Earth Science Information Network database. Accessed at www.ciesin.columbia.edu/indicators/ESI/index.html on January 31, 2005.

Evans, S. 1999. The green republic: A conservation history of Costa Rica. Austin: University of Texas.

Fisher, D. B. and W. R. Freudenburg. 2001. Ecological modernization and its critics: Assessing past and looking toward the future. Society Nat. Resources 14(8):701-708.

Foster, J. B. 1994. The vulnerable planet: A short economic history of the environment. New York: Monthly Review Press.

Frank, D. J., A. Hironaka, and E. Schofer. 2000. The nation-state and the natural environment over the twentieth century. Am. Sociol. Rev. 65(1):96-116.

Freedom House. 2003. Methodology. http://www.freedomhouse.org/template.cfm? page $=35 \&$ year=2003, Accessed March 6, 2005.

Fukuyama, F. 1992. The end of history and the last man. New York: Free Press.

Gardiner, S. M. 2004. The global warming tragedy and the dangerous illusion of the Kyoto Protocol. Ethics Int. Affairs 18(1):23-29.

Hardin, G. 1968. The tragedy of the commons. Science 162(3859):1243-1248.

Hovi, J., T. Skodvin, and S. Andresen. 2003. The persistence of the Kyoto Protocol: Why other annex I countries move on without the United States. Global Environ. Polit. 3(4): $1-23$.

Huber, J. 1982. The lost innocence of ecology. Frankfurt: Fischer Verlag.

Inglehart, R. 1990. Cultural shift in advanced industrial society. Princeton, NJ: Princeton University Press. 
Intergovernmental Panel on Climate Change. 2001. Climate change 2001: Synthesis report, summary for policymakers. A contribution of Working Groups I, II and III to the Third Assessment Report of the Intergovernmental Panel on Climate Change. Cambridge, UK: Cambridge University Press.

Keohane, R. O. 1988. International institutions: Two approaches. Int. Stud. Q. 32(4):379-396.

Kidd, Q. and A.-R. Lee. 1997. Postmaterialist values and the environment: A critique and reappraisal. Social Sci. Q. 78(1):1-15.

Kriesi, H. 1989. New social movements and the new class in the Netherlands. Am. J. Sociol. 94(5):1078-1116.

Leroy, P. and J. van Tatenhove. 2000. Political modernization theory and environmental politics. In Environment and global modernity, eds. G. Spaargaren, A. P. J. Mol, and F. H. Buttel, 187-208. London: Sage.

Lovins, A. B., L. H. Lovins, and P. Hawken. 1999. A road map for natural capitalism. Harvard Business Review 77(3):145-158.

Lutzenhiser, L. 2001. The contours of U.S. climate non-policy. Society Nat. Resources 14(6):511-523.

Marland, G., T. A. Boden, and R. J. Andres. 2001. National $\mathrm{CO}_{2}$ emissions from fossil-fuel burning, cement manufacture, and gas flaring: 1751-1997. Accessed at http://cdiac.esd. ornl.gov/new, March 2005.

Marshall, M. G. and K. Jaggers. 2002. Polity IV project: Dataset users' manual. College Park, MD: University of Maryland, Accessed at www.cidcm.umd.edu/inscr/polity, March 2005.

Maslow, A. 1954. Motivation and personality. New York: Harper.

Mol, A. P. J. 1995. The refinement of production: Ecological modernization theory and the chemical industry. Utrecht, the Netherlands: Van Arkel.

Mol, A. P. J. 2003. Globalization and environment: The ecological modernization of the global economy. Cambridge, MA: MIT Press.

Mol, A. P. J. and F. H. Buttel. 2002. The environmental state under pressure. London: Elsevier.

Molotch, H. and M. Lester. 1975. Accidental news: The great oil spill as local occurrence and national event. Am. J. Sociol. 81(2):235-260.

Murphy, J. 2001. Ecological modernization: The environment and the transformation of society. Research Paper No 20. Oxford, UK: Oxford Centre for the Environment, Ethics and Society, Mansfield College.

Murphy, J. and A. Gouldson. 1998. Integrating environment and economy through ecological modernisation? An assessment of the impact of environmental policy on industrial innovation. OCEES Research Paper No 16. Oxford, UK: Oxford Centre for the Environment, Ethics and Society, Mansfield College, University of Oxford.

O'Connor, J. 1998. Natural causes: Essays in ecological Marxism. New York: Guilford Press.

Oreskes, N. 2004. Beyond the ivory tower: The scientific consensus on climate change. Science 306(5702): 1686.

Ostrom, E. 1990. Governing the commons: The evolution of institutions for collective action. New York: Cambridge University Press.

Parry, M., N. Arnell, T. McMichael, R. Nicholls, P. Martens, S. Kovats, M. Livermore, C. Rosenweig, A. Iglesias, and G. Fischer. 2001. Millions at risk: Defining critical climate change threats and targets. Global Environ. Change 11(3):181-183.

Porter, M. E. and C. van der Linde. 1995. Toward a new conception of the environment-competitiveness relationship. J. Econ. Perspect. 9(4):97-118.

Roberts, J. T. and P. E. Grimes. 1997. Carbon intensity and economic development 1962 1991: A brief exploration of the environmental Kuznets curve. World Dev. 25(2):191-198.

Roberts, J. T., B. C. Parks, and A. A. Vasquez. 2004. Who ratifies environmental treaties and why? Institutionalism, structuralism and participation by 192 nations in 22 treaties. Global Environ. Polit. 4(3):22-64.

Rollings-Magnusson, S. and R. C. Magnusson. 2000. Kyoto protocol: Implications of a flawed but important environmental policy. Can. Public Policy 26(3):347-359.

Schnaiberg, A. and K. A. Gould. 1994. Environment and society: The enduring conflict. New York: St. Martin's Press.

Schnaiberg, A. I. 1980. The environment: From surplus to scarcity. New York: Oxford University Press. 
Schultz, P. W. and L. C. Zelezny. 1998. Values and pro-environmental behavior: A fivecountry study. J. Cross-Cultural Psychol. 29(4):540-558.

Sonnenfeld, D. A. and A. P. J. Mol. 2002a. Globalization and the transformation of environmental governance: An introduction. Am. Behav. Sci. 45(9):1311-1339.

Sonnenfeld, D. A. and A. P. J. Mol. 2002b. Ecological modernization, governance, and globalization: Epilogue. Am. Behav. Sci. 45(9):1456-1461.

Spaargaren, G. 2000. Ecological modernization theory and domestic consumption. J. Environ. Policy Plan. 2(4):323-335.

Spaargaren, G. and A. P. J. Mol. 1992. Sociology, environment, and modernity: Ecological modernization as a theory of social change. Society Nat. Resources 5(4):323-344.

Statistical Abstract of the United States. 1999-2001. Environmental industry: Revenue and employment by industry segment. Washington, DC: U.S. Census Bureau.

Tarde, G. 1903. The laws of imitation, trans. E. C. Parsons. New York: Henry Holt.

United Nations Framework Convention on Climate Change. 2004. Kyoto scoreboard. Accessed at unfecc.int, July 8, 2004.

United Nations Human Development Report. 2003. Millennium development goals: A compact among nations to end human poverty. Accessed at http//hdr.undp.org/reports/global/ 2003, March 5, 2005.

van Kooten, G. C. 2003. Smoke and mirrors: The Kyoto protocol and beyond. Can. Public Policy/Anal. Polit. 29(4):397-415.

Vassilev, R. 1999. Modernization theory revisited: The case of Bulgaria. East Eur. Polit. Societies 13(3):566-599.

York, R., E. A. Rosa, and T. Dietz. 2003. A rift in modernity? Assessing the anthropogenic sources of global climate change with the STIRPAT model. Int. J. Sociol. Social Policy 23(10):31-51.

Young, O. R. 1994. International governance: Protecting the environment in a stateless society. Ithaca, NY: Cornell University Press. 
Copyright of Society \& Natural Resources is the property of Routledge and its content may not be copied or emailed to multiple sites or posted to a listserv without the copyright holder's express written permission. However, users may print, download, or email articles for individual use. 